\title{
Paralytic strabismus correction by adjustable suture technique
}

\author{
P. T. C. DOCHERTY \\ From Derbyshire Royal Infirmary, Derby
}

SUMmaRY The surgical correction of four cases of paralytic strabismus, in which the muscle is repositioned postoperatively with the active co-operation of the patient, is described. The method adopted by the author, by inserting the suture near the limbus, increases the degree of adjustability and allows for more extensive repositioning of the conjunctiva.

The concept of the adjustable suture dates back to Germany in the 1930s. Subsequently other workers ${ }^{1-3}$ have described this method of strabismus surgery. While being suitable for adult cosmetic correction, the adjustable suture has a particularly important and in some cases essential part to play in the correction of paralytic strabismus, for it is here that, with the co-operation of the patient, the return to function in the optimum position can best be achieved. This procedure has perhaps not received the recognition it deserves. Four cases are described here in which its use in paralytic strabismus has given results which would have proved more difficult to obtain without the flexibility of the adjustment.

Correspondence to Mr P. T. C. Docherty, FRCS, Derbyshire Royal Infirmary, London Road, Derby DE1 2QY.

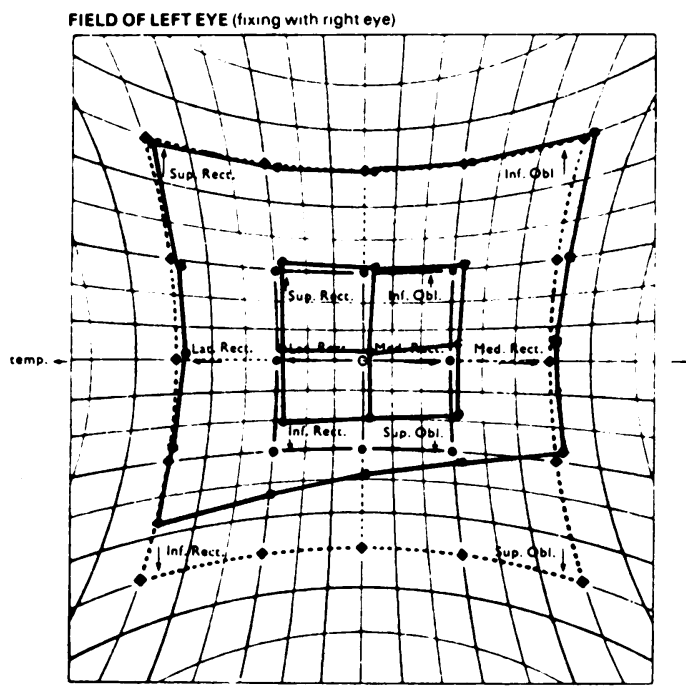

Fig. 1 Case 1. Lee's chart preoperatively.

\section{Case reports}

\section{CASE 1}

A 17-year-old boy was referred to the clinic with diplopia on downward gaze following a road traffic accident 3 months previously. On examination he was noted to have a left superior oblique palsy (Fig. 1) with marked overaction of his right inferior rectus (Fig. 2).

He was kept under observation, but, as no spontaneous improvement occurred over the next 3 months, surgical correction by right inferior rectus recession on an adjustable suture was performed. The following day it was found that the patient had some limitation of depression of the right eye. By advancing the previously recessed right inferior

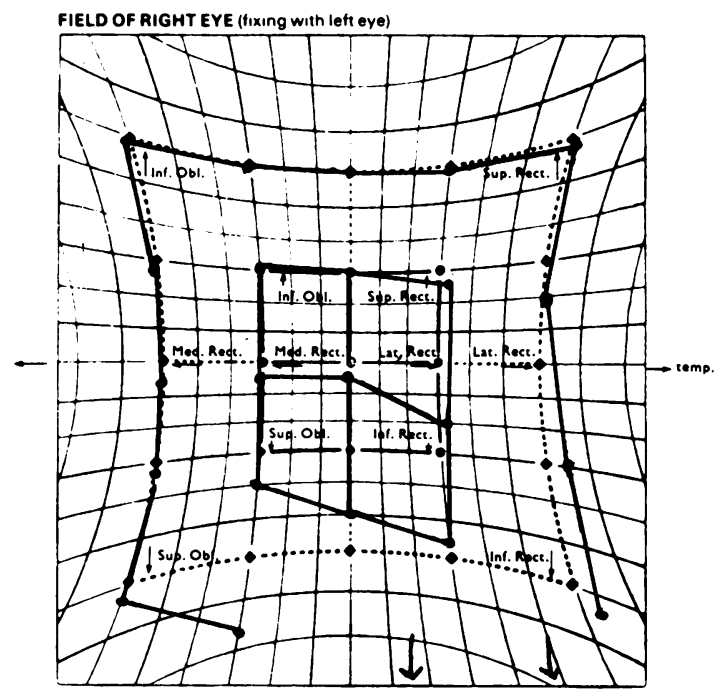




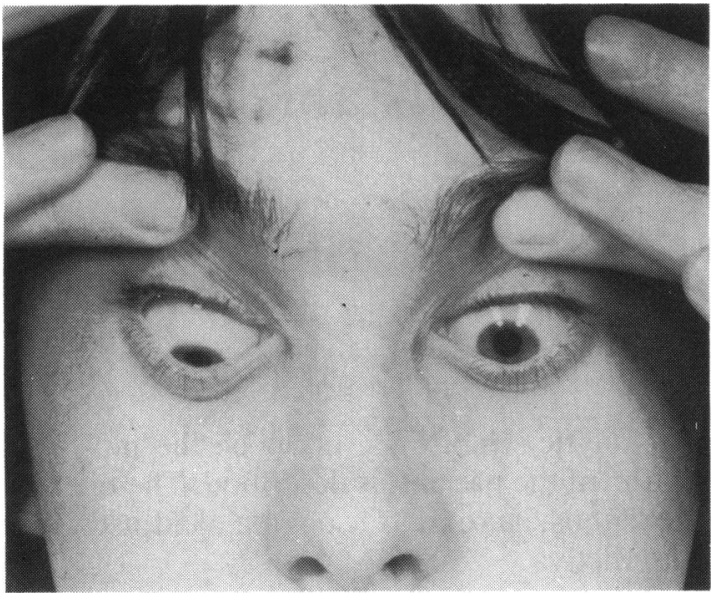

Fig. 2 Case 1. Appearance on downward gaze preoperatively.

rectus, with the patient monitoring his most extensive field of binocular single vision, the optimum position was achieved and the suture tied.

Follow-up visits confirmed that he remained symptom-free. The Lee's chart and the appearance on downward gaze had returned to near normal (Figs. $3,4)$. This situation still obtained 10 months later.

\section{CASE 2}

A 48-year-old woman presented with a 2-year history of diplopia consequent on successful radiotherapy for a rodent ulcer on the medial third of the right lower lid, which was considered to have produced radiation damage to the fibres of the right inferior rectus. The diplopia could be only partly overcome by the use of

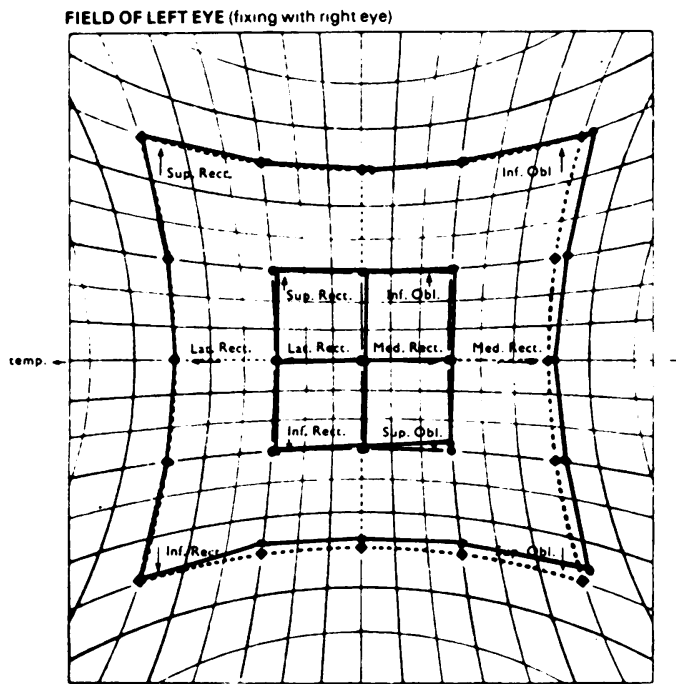

Fig. 3 Case 1. Lee's chart postoperatively.

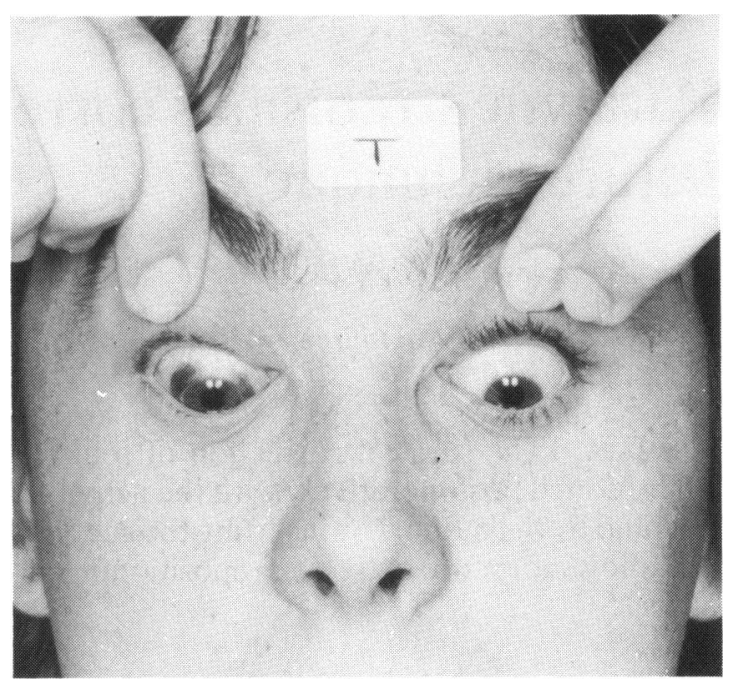

Fig. 4 Case l. Appearance on downward gaze postoperatively.

prisms of increasing strength and by the adoption of abnormal head posture. The Lee's chart revealed weakness of the right inferior rectus with secondary overaction of the left superior oblique (Fig. 5).

A right inferior rectus resection of $3 \mathrm{~mm}$ was carried out, and the adjustable suture was inserted $2.5 \mathrm{~mm}$ anterior to the original insertion. To obtain the maximum field of binocular single vision a small advancement of the right inferior rectus was carried out 24 hours later.

The patient's symptoms resolved, and the Lee's chart returned to normal (Fig. 6). Fourteen months later the patient remained symptom-free.

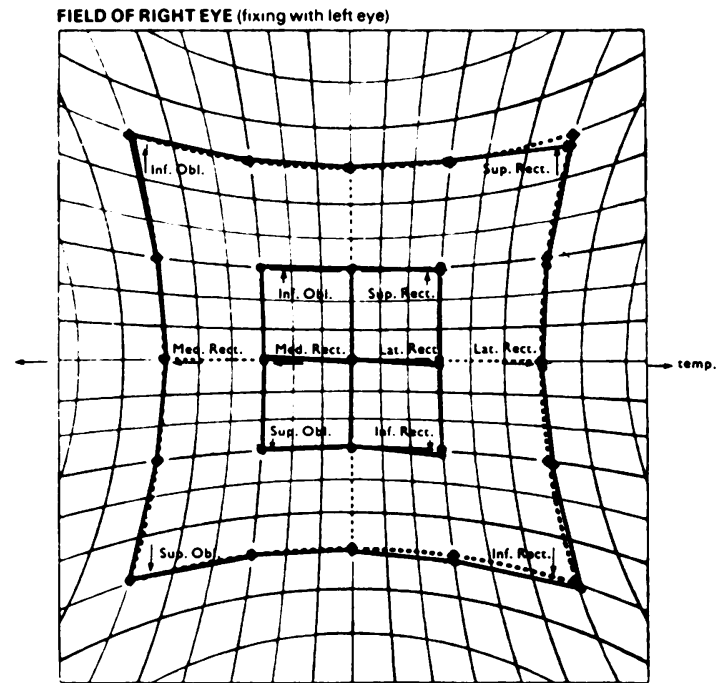




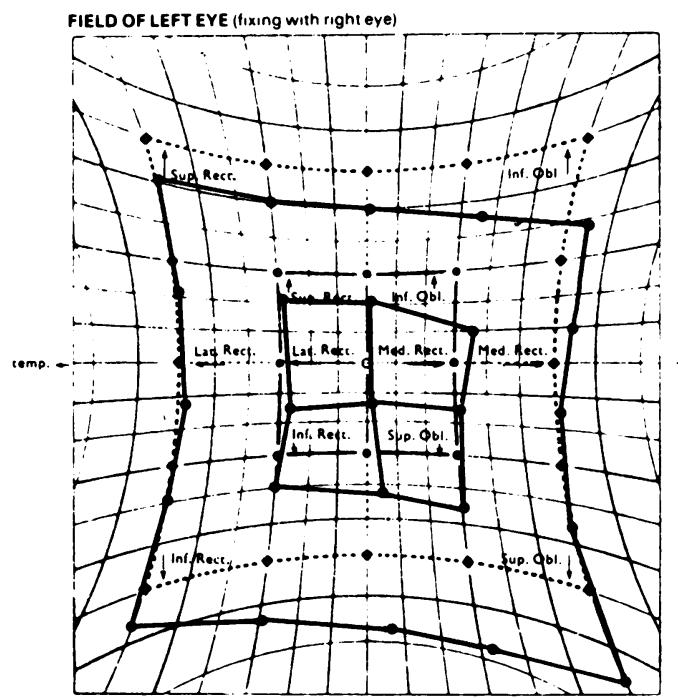

Fig. 5 Case 2. Lee's chart preoperatively.

\section{CASE 3}

A 31-year-old woman presented with a long history of transient diplopia. On orthoptic examination the patient was found to have a left/alternating esotropia in the primary position. She could not abduct the left eye more than $2^{\circ}$ beyond the midline, and to obtain binocular single vision she was forced to adopt an abnormal head posture. This was considered to be a case of Duane's syndrome type B. ${ }^{4}$ A forced duction test on the left medial rectus suggested that it was markedly fibrosed, and the Lee's chart showed this (Fig. 7).

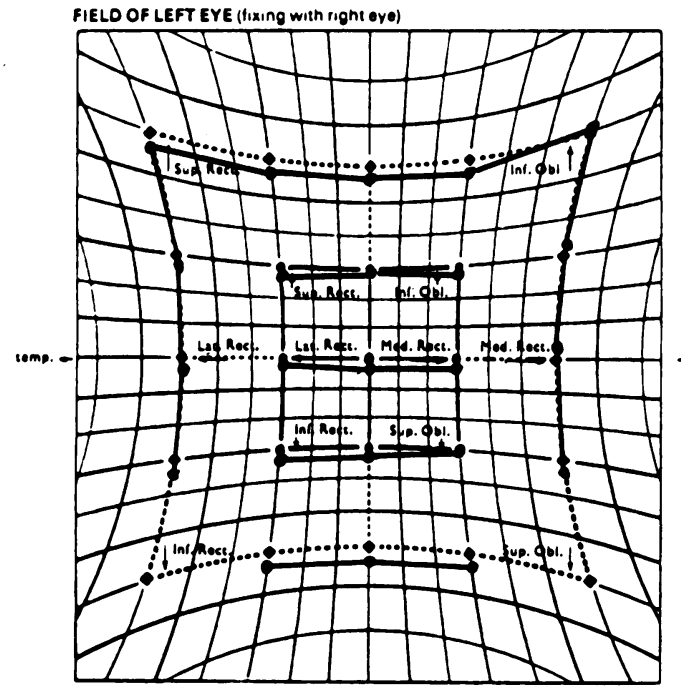

Fig. 6 Case 2. Lee's chart postoperatively.

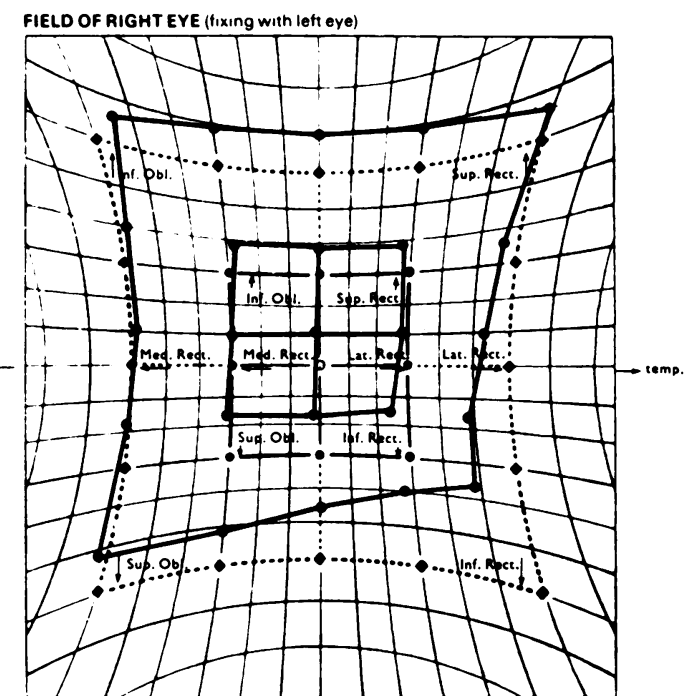

A left medial rectus recession on an adjustable suture was combined with a left lateral rectus resection of $4.0 \mathrm{~mm}$. Postoperatively the patient was noted to have a left exotropia measuring 10 prism dioptres base in at $1 / 3 \mathrm{~m}$ and 14 prism dioptres base in at $6 \mathrm{~m}$ by means of the prism cover test in the primary position. The next day an advancement of the left medial rectus was carried out. Thereafter there was no deviation in the primary position, and abduction of the left eye was much improved (Fig. 8).

Postoperative follow-up confirmed resolution of both the diplopia and the abnormal head posture.

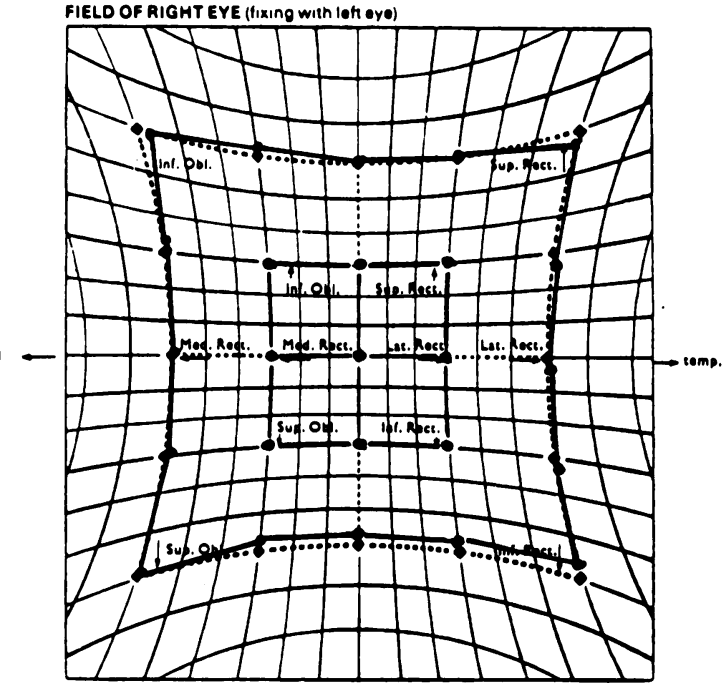



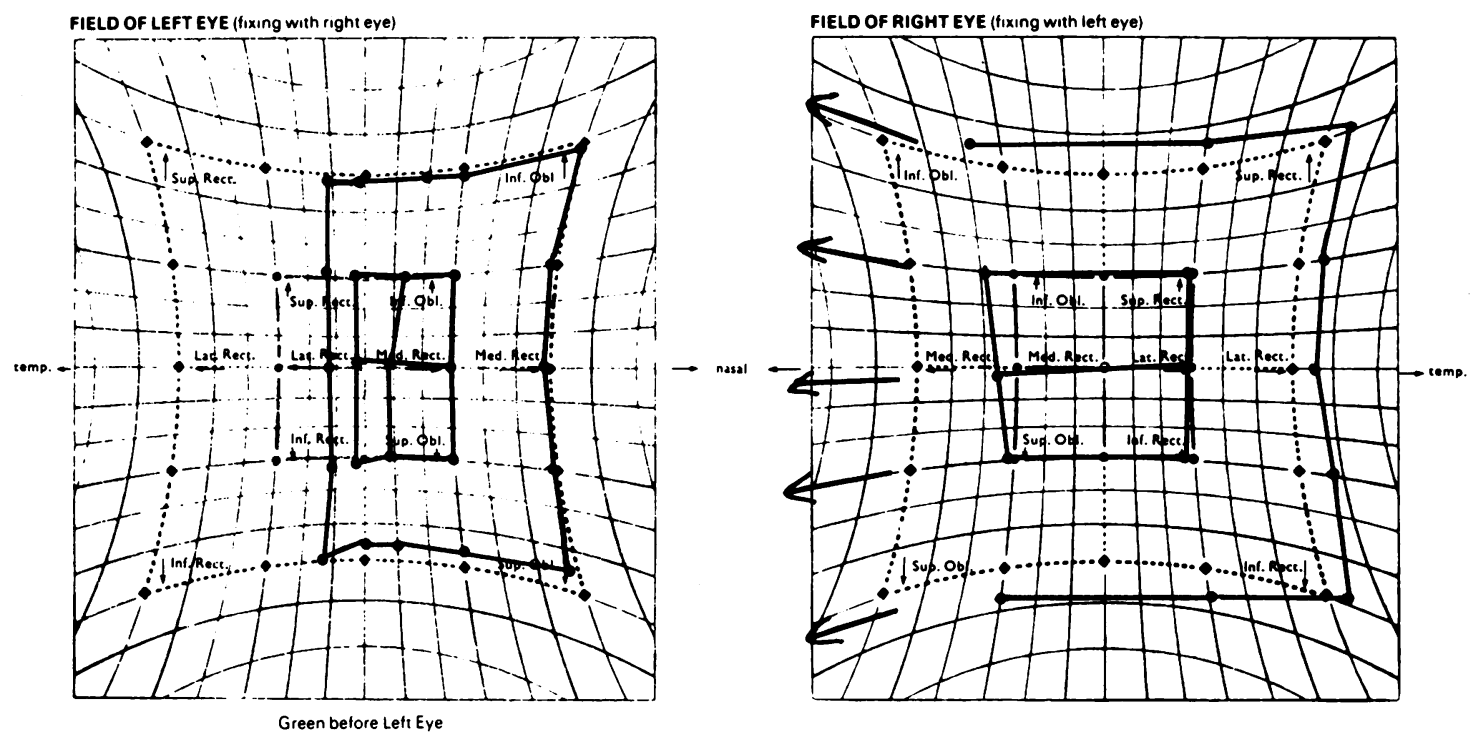

Fig. 7 Case 3. Lee's chart preoperatively.

Review 2 years later confirmed that this patient remained symptom-free.

\section{CASE 4}

A 62-year-old man was referred to the clinic with a complete left sixth nerve palsy consequent to a road traffic accident 2 months previously (Figs. 9, 10). He was examined regularly over the next 4 months, but, as there was no return of lateral rectus function and the possibility of contracture of the medial rectus was increasing, surgical correction was carried out.

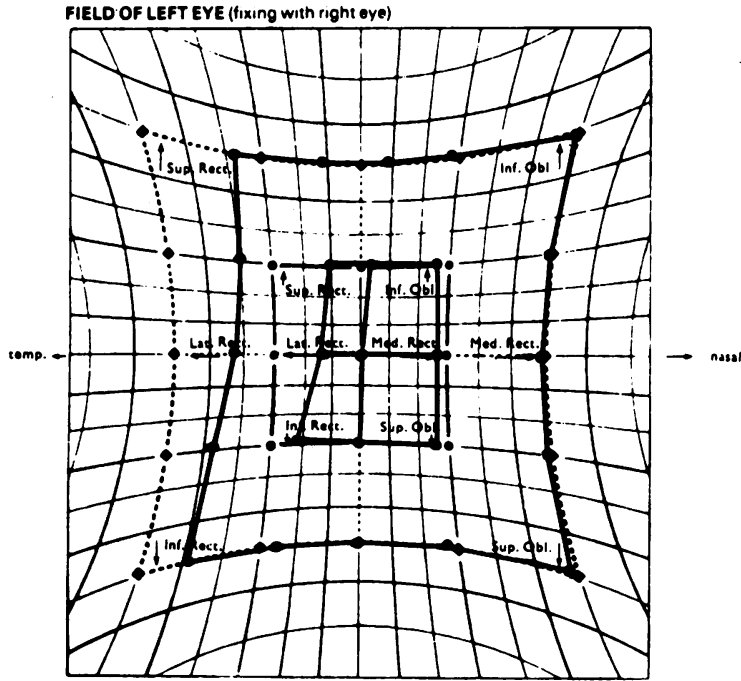

Fig. 8 Case 3. Lee's chart postoperatively.
A left lateral rectus resection coupled with a Jensen procedure was performed, together with a left medial rectus recession on an adjustable suture. ${ }^{5}$ The patient was noted to have a left exotropia next day measuring 20 prism dioptres base in at $1 / 3 \mathrm{~m}$ and 14 prism dioptres base in at $6 \mathrm{~m}$ (Fig. 11). A small advancement of the left medical rectus on the previous day's position produced orthophoria in the primary position.

Examined 9 months later this patient's eye remained cosmetically excellent in the primary position. He was symptom-free both for distance and

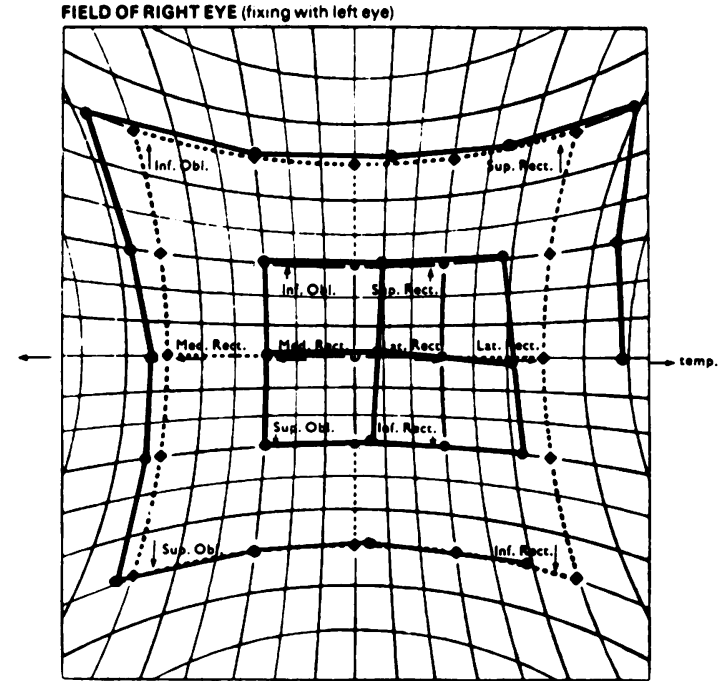



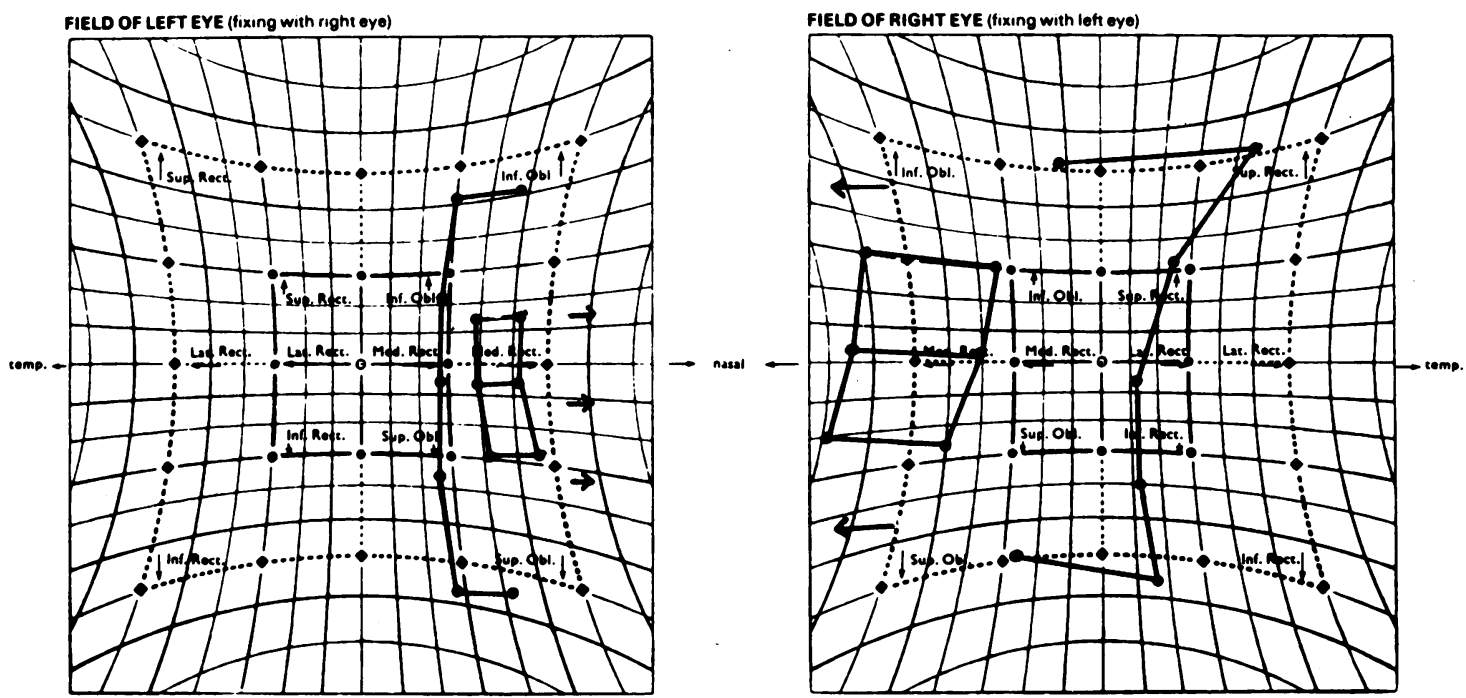

Fig. 9 Case 4. Lee's chart preoperatively.

near, but complained of diplopia on attempted gaze to the left. He was noted to have approximately $7^{\circ}$ of abduction in this left eye (Fig. 12).

\section{Technique}

The conjunctiva is incised parallel to and less than 1 $\mathrm{mm}$ from the limbus. The incision needs to be extended sufficiently to allow the undermined conjunctiva to retract crescentically to expose the muscle insertion. Double locking knots of $6 / 0$ Vicryl are inserted in the exposed muscle insertion or where appropriate for a resection. With the double-ended 8 $\mathrm{mm} 1 / 4$ circle spatulated needles two $2 \mathrm{~mm}$ scleral bites are made approximately $1.5 \mathrm{~mm}$ apart, con-

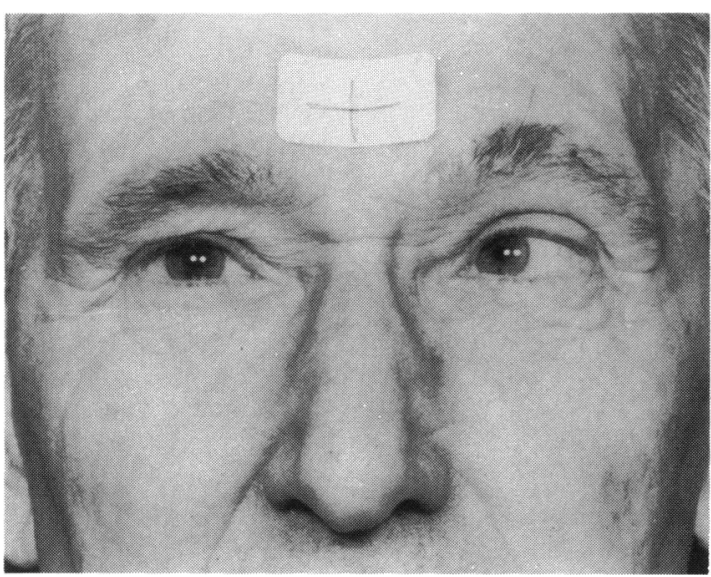

Fig. 10 Case 4. Appearance in primary position preoperatively. verging anteriorly to $1.0 \mathrm{~mm}$. The ends of the suture should emerge some $2.5 \mathrm{~mm}$ from the limbus, as this allows maximum access at the point of adjustment while permitting the most extensive operative realignment of the conjunctiva (Fig. 13). One tie of the surgical knot is usually sufficient to hold, as the $6 / 0$ coated Vicryl braided suture (Ethicon) possesses the most suitable combination of grip, strength, and subsequent adjustability. If the knot does slip, it simply produces a greater degree of recession than originally planned, and the problem can be overcome by advancement.

The limbs of the reflected conjunctiva are reattached with $6 / 0$ plain collagen, the single knot of the $6 / 0$ Vicryl being left exposed within a small tri-

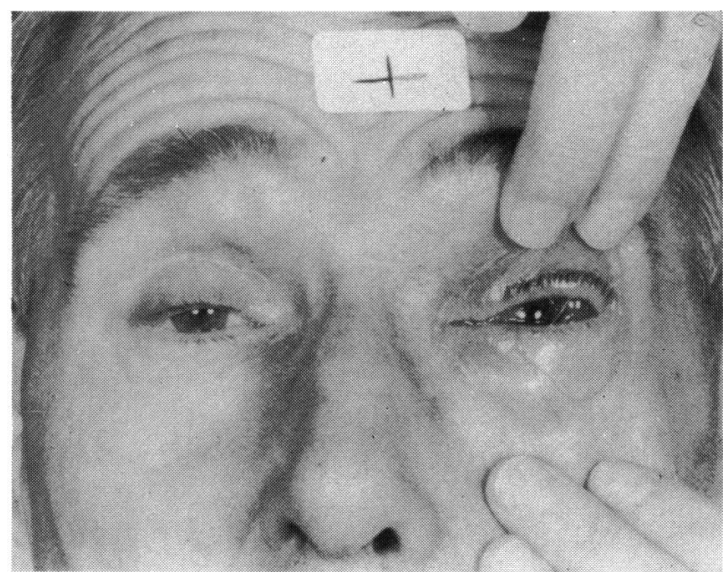

Fig. 11 Case 4. Appearance in primary position postoperatively before adjustment. 


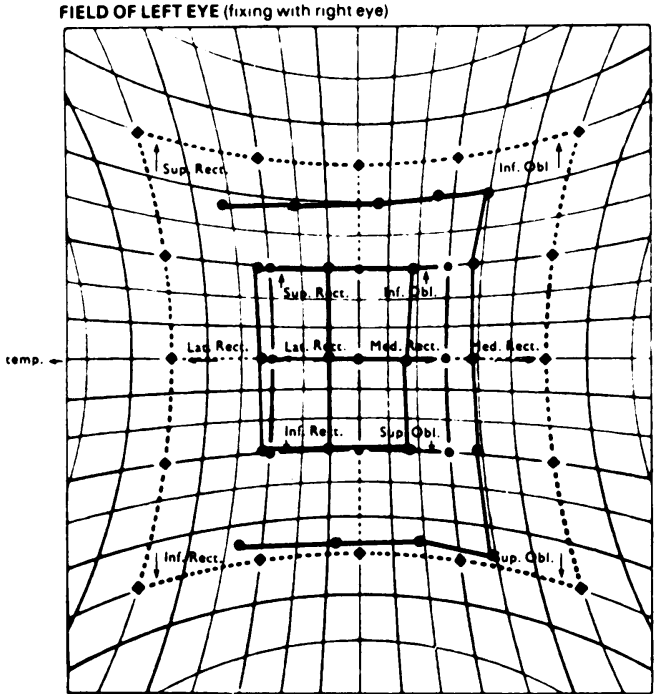

Fig. 12 Case 4. Lee's chart postoperatively.

angular area of conjunctiva (Fig. 14). The author does not attempt to realign the conjunctiva after adjustment with further sutures, but a cotton bud soaked in local anaesthetic may be used gently to position that tissue in order to facilitate more rapid. egression over the knot of $6 / 0$ Vicryl. As a general rule it is wise to over-recess so that advancement is the more likely procedure needed when adjusting, as this invariably proves easier than further recession.

Such is the flexibility of this method that it can be used with almost equal facility for recessions,

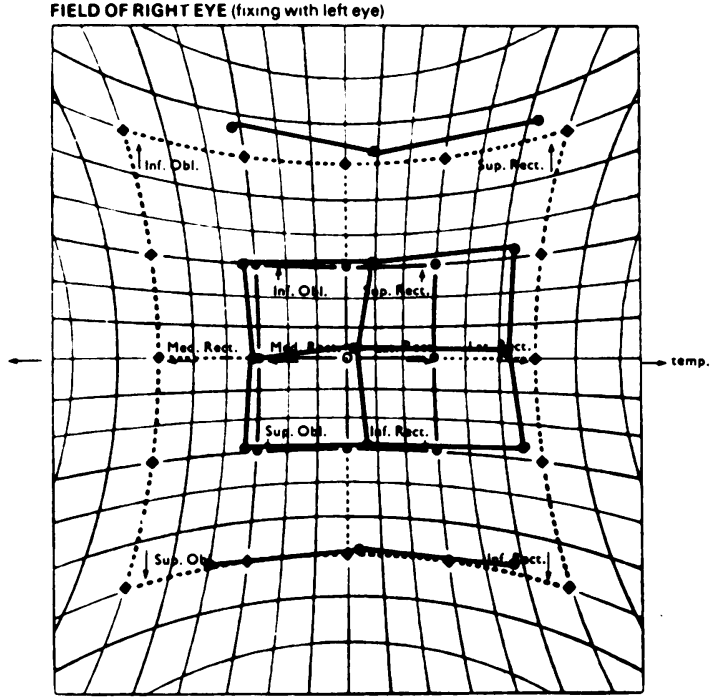

advancements, and combined resection advancements. The method can be readily adapted to incorporate vertical transposition of the horizontal rectus muscles ${ }^{67}$ and horizontal transposition of the vertical rectus muscles. ${ }^{8}$ The loop or handle suggested by Jampolsky has been abandoned by the author. The author leaves the free ends of the suture some 6 $\mathrm{cm}$ long and taped to the cheek (Fig. 11). This has several advantages: it is more comfortable for the patient than having the ends deposited spaghetti-like in the conjunctival sac. Adjustment is easier, and, as

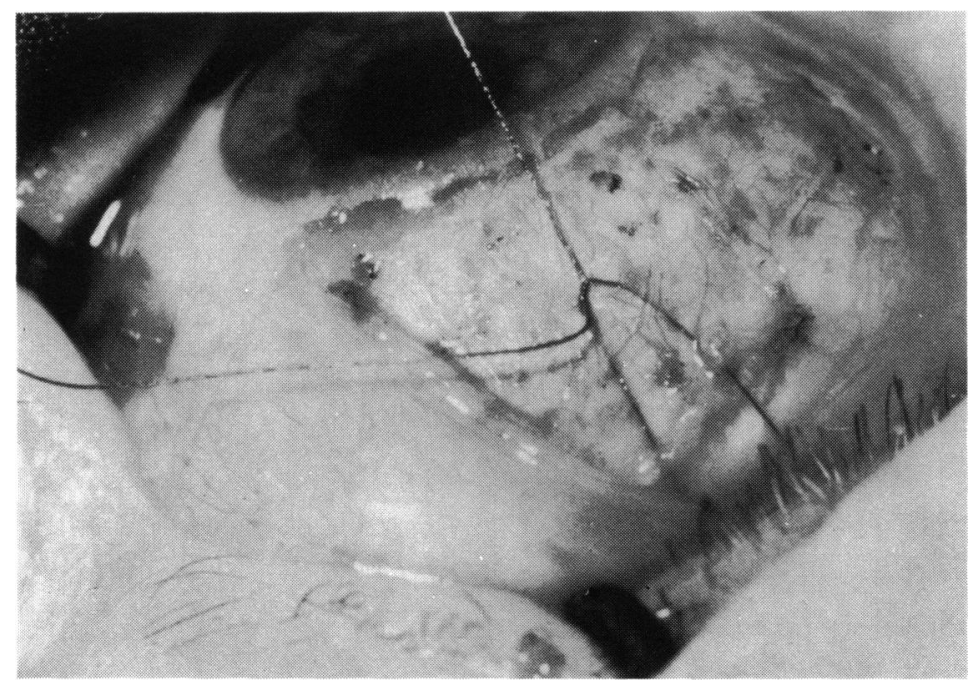

Fig. 13A

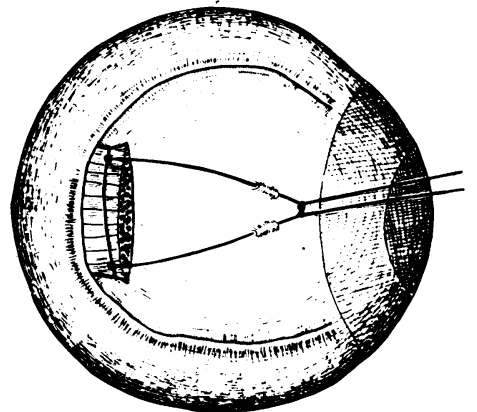

Fig. 13B

Figs. 13A, B Muscle reattached on adjustable suture. 


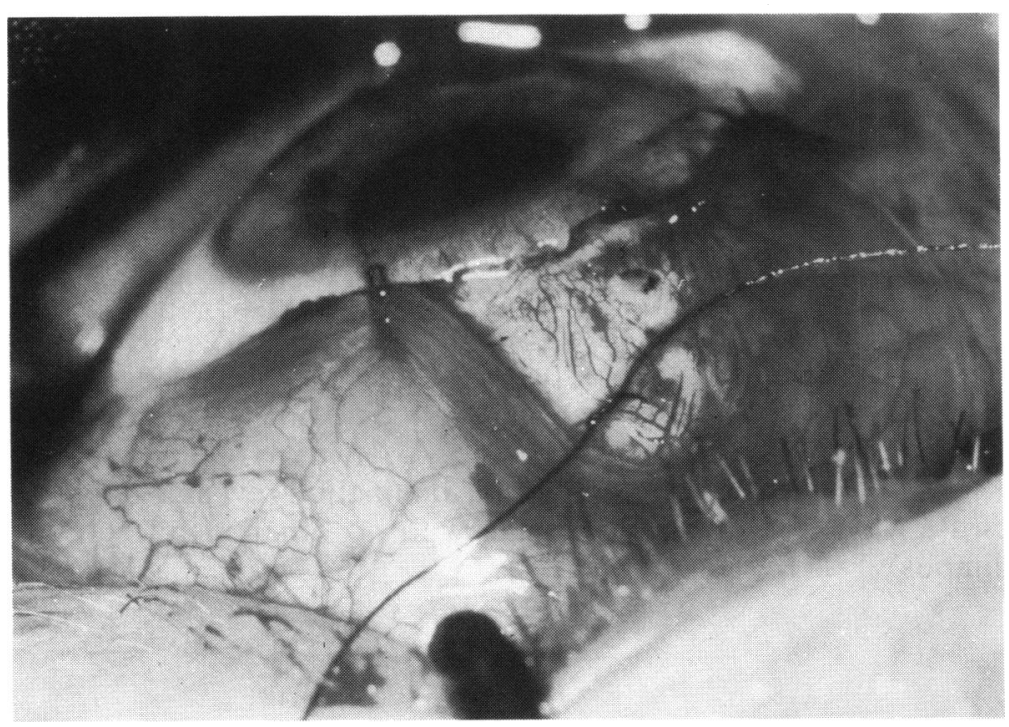

Fig. 14 Conjunctiva realigned with adjustable suture knot exposed.

instrumentation is reduced to a minimum, so too are the patient's apprehensions.

It is advisable to remove the eye-pad 3-4 hours postoperatively to normalise the eye prior to adjustment the following day, and to do the adjustment, if it proves necessary ${ }^{2}$ within 24 hours to avoid the risk of premature adherence, which can occur with alarming rapidity.

Adequate explanation of the technique to the patient is essential to ensure maximum co-operation when adjusting, and as a general rule the author confines the procedure to patients over 16, though each case should be judged on its own merits. As it is desirable to have an alert patient when adjusting, sedation should be kept to a minimum or avoided altogether. Five to 10 minutes cocainisation to the eye before adjustment is sufficient. The postoperative discomfort of the exposed $6 / 0$ Vicryl knot has not proved to be a significant problem.

I acknowledge the help and co-operation extended by orthoptists Margaret Boissier, Elizabeth Evans, and Kathryn Smith, and the
Department of Medical Illustration at the Derbyshire Royal Infirmary.

\section{References}

1 Harms $\mathrm{H}$. Muscular advancement by technique allowing postoperative adjustment. Klin Monatsbl Augenheilkd 1940; 104: 729-33.

2 Rosenbaum AL, Metz HS, Carlson M, Jampolsky AJ. Adjustable rectus muscle recession surgery, a follow-up study. Arch Ophthalmol 1977; 95: 817-20.

3 Jampolsky AJ. Current techniques of adjustable strabismus surgery. Am J Ophthalmol 1979; 88: 406-18.

4 Duane A. Congenital deficiency of abduction associated with impairment of adduction, retraction movements, contraction of the palpebral fissure and oblique movements of the eye. Arch Ophthalmol 1905; 34: 133.

5 Jensen CDF. Rectus muscle union: a new operation for paralysis of the rectus muscles. Trans Pac Coast Otoophthalmol Soc 1964; 45: $359-84$

6 Foster J, Pemberton EC. The effect of operative alterations in the height of the external rectus insertion. BrJ Ophthalmol 1946; 30: 88.

7 Jones ST. Treatment of hypertropia by vertical displacement of horizontal recti. Am Orthopt J 1977; 27: 107-14.

8 Nawratzki I, Benezra D. Transposition of vertical recti for residual tropias. Ann Ophthalmol 1976; 8: 1245-50. 